\title{
Educação infantil em tempo integral: em busca de uma philia social
}

\section{Full-time childhood education: in search of social philia}

\author{
Vania Carvalho de Araújo
}

\begin{abstract}
RESUMO
Este artigo apresenta algumas reflexões decorrentes de pesquisa realizada em diferentes municípios capixabas sobre as concepções e práticas da educação em tempo integral no contexto da educação infantil (ARAÚJO, 2015). A notória existência do "tempo integral" na educação infantil conserva uma durabilidade paradoxal, seja pela sua inescapável formulação em torno dos direitos das mulheres trabalhadoras e das crianças pobres ou em situação de vulnerabilidade e risco social, seja pela sua habitual invisibilidade como parte integrante de um mesmo processo educativo na educação infantil, conferindo-lhe uma identidade instável e uma realidade demandante dos momentos de infortúnio, condicionada que está ao "errante curso labiríntico da vida" (GOETHE apud ARENDT, 1987). Suas questões apontam para a necessária criação de um ethos público, cuja philia social (ARENDT, 1987; MATOS, 2006, 2009; ARISTÓTELES, 2009) se apresenta como uma possibilidade para inaugurar novos suportes materiais e simbólicos que permitam às crianças serem acolhidas para além das contingências de suas necessidades.
\end{abstract}

Palavras-chave: educação infantil em tempo integral; philia social; educação infantil.

\begin{abstract}
This article shows some thoughts which derive from the study undertaken in different Brazilian municipalities from Espírito Santo, Brazil, on the concept and practice of full-time childhood education (ARAÚJO, 2015).
\end{abstract}

DOI: $10.1590 / 0104-4060.47300$

1 Universidade Federal do Espírito Santo. Vitória, Espírito Santo, Brasil. Centro de Educação. Avenida Fernando Ferrari, s/nº. Bairro: Goiabeiras. CEP: 29060-970. E-mail: vcaraujoufes@gmail.com 
The notorious existence of "full-time" in childhood education preserves paradoxical durability, whether by its inescapable formulation around the rights of working women and poor children or children in social vulnerability and risk or by their habitual invisibility as a component of the same educational process in childhood education. This provides an unstable identity and a demanding reality from unfortunate moments, conditioned to "Life's labyrinthine and erratic course" (GOETHE apud ARENDT, 1987). Their questions point to the need of creating a public ethos, whose social philia (ARENDT, 1987; MATOS, 2006, 2009; ARISTÓTELES, 2009) is shown as a possibility to open new material and symbolic supports that allow children to be welcomed beyond their needs.

Keywords: full-time childhood education; social philia; early childhood education.

\section{Introdução}

Fazendo alusão ao poema de Brecht "À posteridade", Hannah Arendt (1987) reúne em seu livro "Homens em tempos sombrios", uma coletânea de conferências, ensaios e resenhas, destacando algumas figuras humanas de seu tempo - Rosa de Luxemburgo, Karl Jaspers, Heidegger, Angelo Roncalli, Walter Benjamin, Lessing, dentre outros -, que atravessaram tempos adversos, desastres morais e catástrofes políticas, extraindo deles grandes inspirações ao seu pensamento e à sua experiência pessoal.

Dos "tempos sombrios" inaugurados com o totalitarismo nazista e stalinista, como bem destaca Arendt, a ausência de mundanidade se apresenta como consequência de uma época, cujos parâmetros de convivialidade humana converteram-se em uma mixórdia de interesses privados e na negação de uma esfera pública compartilhada. Evidente que Arendt discorre sobre as perplexidades de um tempo que não estabelece uma relação equidistante com o nosso, ao contrário, sua sobrevivência, ainda que em proporções distintas, encontra guarida na extensão dos critérios utilitaristas e pragmáticos da modernidade capitalista, cuja "temporalidade é a do efêmero, do descartável". (MATOS, 2006, p. 155). Um dos seus efeitos está na ascensão da privatividade e na felicidade pública como privilégio de uma minoria. (ARENDT, 2011. Opera-se, assim, um modo de arbitrar sobre o que é justo e injusto, verdade e mentira, o bem e o mal e, num mundo repleto de incertezas e riscos, resta-nos um presente petrificado pelas armadilhas da repetição enredada que está ao "reino da necessidade". 
Se na modernidade "[...] há a falência da compreensão humanista da democracia e da cidadania, inseparáveis, que eram estas, da vida ética" (MATOS, 2006, p. 155), seus reflexos estão por produzir um tempo estranho, um "tempo inteiramente fetichizado". O tempo inteiramente fetichizado, sublinha Matos (2006, p. 79), “[...] é o do presente perpétuo, aquele em que a repetição contínua das mesmas pseudonovidades faz desaparecer toda a memória histórica a fim de que nenhum acontecimento possa mais ser compreendido em suas causas e consequências".

Em uma sociedade como a nossa, voltada à funcionalidade da vida, onde "o público foi despojado de seus conteúdos diferenciais e ficou sem agenda própria", como destaca Bauman (2000, p. 71 ), tudo passa pela imediatez do mérito da utilidade, deixando transparecer uma hierarquia de necessidades que termina por subverter o sentido mesmo da cidadania, da democracia e dos direitos, ao mesmo tempo em que despotencializa a criação de uma cultura pública, cujas prerrogativas têm como horizonte uma responsabilidade ético-política com as garantias da proteção e da provisão social.

Novamente recorremos à Arendt (1987) ao tomar de Goethe um pequeno fragmento contido em sua dedicatória a Fausto, quando a memória dos enredos trágicos revela o passado ao reexperimentar o que se fez sob o sofrimento. "A dor se renova, o lamento repete o errante curso labiríntico da vida". Contudo, Arendt (1987, p. 28) ressalta: "Não podemos dominar o passado mais do que desfazê-lo. Mas podemos nos reconciliar com ele". Assim, rememorar o passado, tal como o lamento do poeta, significa tornar também audíveis e visíveis nossos feitos e ações, de modo que as experiências possam ser narradas e não esquecidas. Arendt ressalta que, reconciliarmos com o passado não significa extrair dele o inaudito e nem mesmo vergarmos sobre ele, mas, tal como a atividade do pensar nos evoca, desalojar padrões estabelecidos e práticas cristalizadas.

Essas reflexões nos desafiam a discorrer sobre a emergência cada vez mais pujante da oferta e ampliação da educação infantil em tempo integral. Sua notória existência na sociedade brasileira, ao longo de décadas, conserva uma durabilidade paradoxal na contemporaneidade, seja pela sua inescapável formulação em torno dos direitos das mulheres trabalhadoras e das crianças pobres ou em situação de vulnerabilidade e risco social, seja pela sua habitual invisibilidade como parte integrante de um mesmo processo educativo na educação infantil, conferindo-lhe uma identidade instável e uma realidade demandante dos momentos de infortúnio, condicionada que está ao "errante curso labiríntico da vida".

Assim, estamos mais próximos de submeter as crianças a uma lógica temporal que delimita sua inclusão na sociedade, reeditando uma "educação assistencialista" (KUHLMANN JR., 2000), do que promover uma cultura pública capaz de ampliar as possibilidades de escolha da família sobre os destinos 
de seus filhos, principalmente em um contexto de "exaurimento" das formas pelas quais as famílias tentam equacionar, como bem ressalta Gama (2012), as tensões entre trabalho e vida familiar.

E é nessa assimetria entre famílias preocupadas em resolver suas próprias necessidades e demandas particulares e a emergência de reconhecer as crianças não pela privatização de suas demandas, mas pelo reconhecimento público de seus direitos, que se fazem necessárias políticas públicas orientadas por uma cidadania compartilhada. A erosão de uma cultura pública não apenas produz uma vida social privatizada, mas deixa o indivíduo prisioneiro, como diria Arendt (2011, p. 67-68), “[...] da subjetividade de sua própria existência singular”.

É o que acontece quando o acesso de crianças às instituições em tempo integral na educação infantil, além de tipificar direitos pela via meritocrática inferiorizada - mais vulneráveis, pobres e em situação de risco social -, não consegue plasmar outras formas de sociabilidades, recluso que está a uma temporalidade aderida à manutenção da vida e não da experiência, o que remeteria a outros tempos sociais e não a um tempo fetichizado e administrado segundo as contingências das necessidades das crianças e de suas famílias (aqui a ordem do necessário se exaure quando a vaga é "conquistada"/garantida). Sem falar no emprego de uma imagem associada ao velho discurso da moralidade social quando, indistintamente, situa a jornada ampliada como instância capaz de suprir determinadas carências das crianças e "deficiências" protetivas de suas famílias e da própria sociedade. É a nossa sociedade escolarizada, "incapaz de pensar a educação de outra maneira que não seja a escolar", como afirma Brayner (2008, p. 85).

Lançando mão de uma pesquisa realizada em dez municípios capixabas sobre as concepções e as práticas da Educação Infantil em tempo integral no Estado do Espírito Santo (ARAÚJO, 2015)² e ousando desalojar padrões estabelecidos, entramos mesmo na interioridade de questões que se apresentam como uma realidade subsumida pelos automatismos e pelas contingências da vida cotidiana. Isso explica, em grande parte, a frequente recorrência ao "tempo integral" como uma temporalidade mais próxima do viver do que da "arte do conviver", mais próxima de um ambiente hostil, do que da felicidade pública, mobilizadora essa, de uma philia social. Essa temporalidade linear, aderida à necessidade, parece agregar duas lógicas temporais: uma que se inscreve, parafraseando Telles (1999, p. 127), na questão social como tarefa de um Estado redentor e, outra que, na sintonia com o mercado e com o reinado da necessidade, forja um laço social à distância com reduzidas formas de conviver.

2 Estudo exploratório quanti-qualitativo realizado por meio de um Termo de Cooperação Técnica entre UFES e MEC, com financiamento do FNDE . 
Ao observarmos os critérios que se estabelecem por meio de tais lógicas, uma institucionalidade voltada à proteção das crianças se esconde sob a ausência de uma cultura pública, cujos mecanismos se desenvolvem por meio de um refúgio enredado ao próprio "reino da necessidade".

Tal como a invenção moderna do século XVIII, ressaltada por Sennett (1988, p. 31), quando “[...] o 'público' veio a significar uma vida que se passa fora da vida da família e dos amigos íntimos; na região pública, grupos sociais complexos e díspares teriam que entrar em contato inelutavelmente [...]", a "criança cosmopolita" se movimenta em meio à diversidade, devendo então comportar-se de um modo emocionalmente e socialmente satisfatório como exigência de civilidade. Isso remete aos inúmeros constrangimentos que se colocam na dimensão pública da vida, sobretudo no que diz respeito a uma sociedade que prometeu direitos e bem-estar social, mas não foi capaz de promover relações éticas e estéticas estáveis que assegurassem experiências humanas mais duradouras, transformando a experiência da vida comunal, conforme destaca ainda Sennett (1988), em uma experiência de "fratricídio".

Se a cultura pública diz respeito ao modo como as relações se efetivam, o simples reconhecimento do direito pelo imperativo da necessidade sempre expõe um aspecto individualizado e restrito desse direito, além de não se revelar como suficiente na efetiva estruturação de uma vida comum, mesmo que tal reconhecimento faça parte de uma prerrogativa democrática.

Situando tais reflexões ao âmbito da formalização do direito à educação infantil em tempo integral, podemos afirmar que a oportunidade de acesso circunscrita a um reconhecimento legal dos "mais necessitados" amplia o reconhecimento do direito, mas, conforme expressa Gentili (2009) acerca do ideal de uma escolaridade comum conquistada no espaço formal,

[...] acolhe os sujeitos de forma desigual em função de certos atributos que os princípios democráticos condenam, pelo menos eticamente: a cor da pele, seu grupo étnico de origem, o gênero, a região ou o bairro onde moram, a profissão do pai e da mãe, seus salários (ou a falta deles), etc. Nestes termos a escola universalizou-se sem ampliar ou democratizar sua condição 'pública', isto é, sem que se tenha ampliado seu status de bem comum, de direito social desmercantilizado e atravessado por uma radical aspiração a melhorar de forma permanente a socialização de seus benefícios. (GENTILI, 2009, p. 5).

Em se tratando do acesso à educação infantil em tempo integral, duas questões valem aqui destacar: a primeira refere-se à universalização de seu direito 
como algo que ainda não se constituiu em uma realidade (o que não significa questionar tal prerrogativa), pois certos atributos necessários para acessá-lo estão atrelados a certas condicionalidades, tais como, situação de vulnerabilidade, pobreza, risco social etc. A segunda, diz respeito à complexidade da vida produzindo uma forma compulsória de proteção e prevenção, na qual as instituições de educação infantil se apresentam como um símbolo mediador de direitos, não implicando outras formas de objetivos e significações partilhadas e nem mesmo reconhecimento de "cidadania extensiva", já que a jornada ampliada continua a se constituir como um dispositivo da mãe trabalhadora e uma estratégia recriada para atender os valores do mercado. Como bem destaca Sposati (2007),

Os projetos de fundamentação liberal-social ou economicista [...] negam o reconhecimento do direito de cidadania extensivo e consideram a atenção social compatível somente a grupos focais caracterizados pelo grau de indigência estabelecido sob alta seletividade. Nesse caso o acesso social depende do prévio enquadramento do cidadão à condição de necessitado, sem direito a requerer atenção a sua necessidade social. (SPOSATI, 2007, p. 437).

Tudo isso exige pensar sobre as novas formas de exclusão das crianças na vida pública e em que medida os interesses das crianças estão sendo também considerados, como bem nos lembra Qvortrup (2015), principalmente quando demandam outros espaços para ficarem: a própria casa, a casa da avó, a casa dos amigos, a rua etc. " ${ }^{3}$ Com a vida completamente administrada, a criança se torna ainda mais dependente. O resultado é um controle mais efetivo e uma administração total do tempo da infância". (SIERRA, 2004, p. 39).

\section{Por uma philia social}

Com a formalização de uma nova perspectiva programática e pragmática da educação infantil em tempo integral, proposta pelo atual Plano Nacional de Educação (BRASIL, 2014), pergunta-se: é possível pensá-la como espaço gerador de outras formas de sociabilidades públicas? Reduzir o mundo social

3 Essas respostas foram decorrentes das perguntas dirigidas às crianças de três e cinco anos, moradoras de contextos rurais e urbanos, em pesquisa anteriormente citada. 
e cultural ao campo da escola seria o mesmo que reforçar uma demasiada institucionalização e judicialização da infância. Contudo, sabemos o quanto a escola pode revelar-se como espaço potente de proteção sem desvencilhar-se da experiência promotora de uma philia social, qual seja, daquela amizade capaz de criar novos liames entre adultos e crianças, entre a instituição escolar e a cidade.

Para os gregos da antiguidade clássica, philia era a amizade entre os cidadãos e philantropia significava "[...] amor dos homens, presteza em partilhar o mundo com outros homens". (ARENDT, 1987, p. 31). A amizade era a chave e o fundamento da vida social, a possibilidade de laços mais duradouros na comunidade. Para Aristóteles (2009), na Ética a Nicômaco, o amigo é aquele com quem compartilhamos as nossas dores e alegrias. Para ele, a concórdia só existe quando há uma coincidência de propósitos e cada um deseja a mesma coisa para o outro. Daí porque a concórdia é definida como a amizade política.

A concórdia parece [...] um certo laço de amizade que une os cidadãos em torno de determinado objetivo, a saber, dos seus interesses comuns e das coisas concernentes à vida de todos os dias. A concórdia assim caracterizada existe entre as pessoas de bem, pois concordam consigo próprios no seu íntimo e uns com os outros, na medida em que, se assim se pode dizer, existem assentes sobre si próprios (os seus desejos permanecem e não fluem e refluem como a maré em Euripo), desejam o que é justo e o que é de interesse comum, e é, portanto, para esses objetivos que se lançam em conjunto. (ARISTÓTELES, 2009, p. 207-208).

Ao contrário de ser uma condição da alma, um "amor platônico", em Aristóteles, philia corresponde a uma atividade filosófica, expressão de uma atitude moral e intelectual. Essa "desafetivação" e a ênfase no seu aspecto racional, ressalta Ortega (2002),

[...] permite sublinhar a ligação da philia com a excelência moral e sua importância para a vida boa (eudaimonia), bem como ampliar a gramática da philia, estendida quase à totalidade das relações humanas, e fazer uma forte ligação com a política e a justiça, no seu enfoque da amizade civil ou política (politike philia). (ORTEGA, 2002, p. 38).

Enquanto para Aristóteles a amizade constitui a expressão de uma atitude de amor que experiencia a arte do com-viver como fundamento para o bem- 
-viver e cujos esforços conjuntos tendem à felicidade pública, a hospitalidade, para Homero, "[...] era uma prova de acolhimento e de civilidade que podia garantir tanto a segurança física do indivíduo quanto à integridade social da comunidade. [...] um forte vínculo de proteção com aquele que se encontra em situação adversa" (FREITAS, 2014, p. 35).

Ao ressaltar que a amizade exprime mais humanidade do que a fraternidade, sobretudo por estar mais voltada ao público e não a uma comunidade de iguais, a amizade em Arendt constitui uma forma de sociabilidade, uma experiência pública compartilhada tendo por base o amor mundi que, ao contrário de um sentimento amoroso ou da expressão de uma intimidade cultivada em si mesma, expressa uma responsabilidade com o mundo comum, com a existência de um espaço compartilhado por uma pluralidade de pessoas. "[...] o amor mundi de Arendt significa não apenas uma promessa que une seres humanos, mas, sobretudo, um imperativo à ação". (ASSY, 2015, p. xxxvi).

Segundo Ortega, em seu livro "Para uma política da amizade: Arendt, Derrida, Foucault" (2009),

\begin{abstract}
Somente desenvolvendo novas formas de amor mundi no sentido arendtiano que, a meu ver, podemos conceber alternativas a esse ideal, criar e recriar formas de relacionamento voltadas para o mundo, para o espaço público, tais como a amizade, a cortesia, a solidariedade, a hospitalidade, o respeito. Todas elas dependem de um espaço de visibilidade capaz de iluminar os acontecimentos humanos, de um mundo comum que una ou separe os indivíduos, mantendo sempre a distância entre eles, condição da pluralidade. (ORTEGA, 2009, p. 30).
\end{abstract}

A pluralidade em Arendt é aquilo que nos possibilita estabelecer uma experiência humana compartilhada, um mundo comum, já que o fato de estarmos em companhia de outros seres humanos singulares requer que nos comuniquemos uns com os outros. Assim, "[...] a pluralidade humana é a paradoxal pluralidade de seres únicos" (ARENDT, 2010, p. 220), o que significa dizer que a existência de cada um pode ser reconhecida como algo dotado de sentido na construção de uma esfera pública compartilhada. O mundo comum, por sua vez, não é uma realidade dada e nem mesmo garantida, se constituindo exatamente quando, não obstante, as diferentes perspectivas e ângulos, todos se voltam e se interessam pelos mesmos objetivos e horizonte de possibilidades, quais sejam, a transformação do mundo em uma comunidade de sentido, de heranças partilhadas. Contudo, “[...] se o mundo deve conter um espaço público, 
não pode ser construído apenas para uma geração e planejado somente para os que estão vivos, mas tem de transcender a duração da vida de homens mortais". (ARENDT, 2010, p. 67). Isso explica porque para os gregos o mundo deveria constituir-se em um "lar imortal para seres mortais".

Enquanto o "não mundo" representa a destruição de um espaço que nos permite ser humanos, estar-em-relação e construir um mundo comum, o "amor mundi" diz respeito a uma ética da responsabilidade com aqueles que chegam ao mundo, voltada que está à condição humana de partilhar um mundo comum com as novas gerações. A ausência de mundanidade (o não-mundo), para Arendt, é sempre uma forma de barbárie, pois uma vez perdida uma comunidade de coisas que nos reúne num mundo de realizações simbólicas e materiais de uma cultura, perdemos os critérios que nos orientavam no mundo e ficamos presos às contingências da convivência humana. E o que seria essa responsabilidade pelo mundo? É o ponto em que decidimos se amamos o mundo o bastante para nos responsabilizarmos por ele.

Assim destaca Telles (1999), inspirada em Arendt:

A perda do mundo comum constrói a figura do indivíduo interessado e desprovido de responsabilidade perante o mundo. Para esse indivíduo, o outro pouco importa e pouco conta, sua existência ou não existência não faz a menor diferença. Equivale à experiência de indivíduos que se tornaram supérfluos no mundo. (TELLES, 1999, p. 48).

Tornarmo-nos responsáveis pelas questões que dizem respeito à vida das crianças parece ser uma chave importante para refletirmos sobre uma realidade cujas demandas sempre se mantiveram sob a égide da hierarquização dos benefícios públicos - principalmente em relação às crianças pobres -, mas que não chegam a plasmar uma noção de direitos como forma de sociabilidade política e nem mesmo uma philia social.

Se o imperativo da necessidade ainda diz muito de uma sociedade que se tornou pública por uma ação estatal ou pela garantia formal de direitos, essa mesma necessidade deve ser recolocada no âmbito das corresponsabilidades públicas. Caso contrário, os "supérfluos para o mundo" continuariam reconhecidos apenas na sua elementaridade e como prisioneiros de sua própria existência singular e de suas carências, cujo resultado é a comoção pública e não a efetividade do direito. Nesse caso, é preciso levar em consideração que "[...] as crianças não têm somente necessidades, mas fundamentalmente direitos", conforme nos lembra Soares (2015, p. 9). 
Não obstante a abrangência e a complexidade do pensamento de Arendt, bem como a crítica endereçada ao seu pensamento sobre uma certa ênfase na subalternidade da criança frente aos adultos, o que não corresponde aos fundamentos de suas reflexões, podemos extrair de seu esforço analítico um exercício teórico ímpar de contrapor-se à exagerada preocupação da educação em instruir as crianças e mantê-las artificialmente em seu próprio mundo e na arte de viver, separadas que estão do mundo dos adultos. Seu objetivo, como ela mesma afirma no prólogo de seu livro "A condição humana" (2010), não é oferecer respostas às preocupações e perplexidades de seu tempo. "Trata-se apenas de pensar o que estamos fazendo". (ARENDT, 2010, p. 6).

Suas reflexões nos ajudam a pensar sobre a forma arbitrária com que o direito à educação infantil em tempo integral tem reposto algumas questões dilemáticas de nossas experiências com as crianças, principalmente quando o reconhecimento desse direito passa a ter visibilidade pelo viés da discriminação positiva e não pelo reconhecimento público das condições de vida diferenciadas.

A subalternidade das crianças em relação às decisões dos adultos sempre foi utilizada como um artifício de cuidado e proteção, contudo, outras evidências demonstram a controvérsia de tais enunciados quando se apresentam de modo naturalizado e unívoco. Isso nos remete a pensar sobre as formas reinventadas de institucionalização da infância que negam às crianças a possibilidade de compartilhar um destino comum com outras crianças e adultos, inaugurando-se, assim, uma pragmática que se propõe a salvaguardar proteção e direitos sem questionar as iniquidades resguardadas com o acesso à lei e a uma noção de direito que não geram novas sociabilidades públicas e nem mesmo convertem-se em um bem-estar social e cultural.

Estabelecer determinadas condicionalidades para acesso e permanência na educação infantil em tempo integral pode subverter a asserção ao direito por uma lógica perversa da diferença, além de não implicar, necessariamente, na superação das desigualdades sociais por que passam as crianças e suas famílias. A limitação de outras formas de participação social e de convivência entre as crianças de distintos contextos sociais, culturais e econômicos pode transformar as discriminações positivas numa espécie de privação de um mundo de valores e significações partilhadas, já que partilha significa troca, alteridades entre narrativas, culturas e repertório humanos plurais. 


\section{Considerações finais}

Ao relacionar a temporalidade institucionalmente organizada como correspondente a um acolhimento da experiência na vida social, Matos (2009) chama a atenção para os efeitos de uma "temporalidade aderida ao presente". Tal presenteísmo, segundo Matos (2009, p. 92),

[...] apodera-se de todos os espaços democráticos, a começar a educação que deixa de ser "educação para a liberdade", para direitos e deveres correspondentes, tornando-se "educação para a adaptação", na proliferação de direitos sem a Lei pan-inclusiva que deveria presidi-los. (MATOS, 2009, p. 92).

Esse "culto dos meios e esquecimento dos fins", criado pela modernidade ocidental, é uma prova do quanto se faz necessário recuperar valores que remetam a uma experiência pública compartilhada, a uma philia social capaz de romper com os automatismos da vida e com a perda de sentido de nossas ações no mundo. Se a "educação para a adaptação" nos remete ao modo como o "mérito da necessidade" tornou-se uma instância de mediação societária e como as crianças são introduzidas em processos de institucionalização que as impedem de acessar outros universos culturais e outros vínculos sociais, por outro lado, nos remete também às possibilidades de pensar as prerrogativas do direito à educação infantil em tempo integral tendo como horizonte uma sociedade que não deixa as crianças fixadas na natureza mesma de sua existência singular e nas contingências da necessidade, mas tomam para si a responsabilidade de apresentar o mundo às crianças para que elas possam criar novos mundos.

Sob esse prisma, o acesso à educação infantil em tempo integral não deve ser pensado sob uma forma "condicionada ou subalternizada" do direito (GENTILI, 2009), mas como um modus operandi de uma philia social e de um ethos público, cuja temporalidade se responsabiliza com a criação de novos suportes materiais e simbólicos que introduzem as crianças na arte do com-viver e do bem-viver.

4 Expressão utilizada por Vera Telles (1999) ao reportar-se à reflexão de Aldaíza Sposati (1988) sobre a obrigação de determinados tipos de sujeitos comprovarem suas incapacidades e carências socais para obtenção do reconhecimento público de suas necessidades. 


\section{REFERÊNCIAS}

ARAÚJO, V. C. de. O tempo integral na educação infantil: uma análise de suas concepções e práticas. In: ARAÚJO, V. C. de (Org.). Educação infantil em jornada de tempo integral: dilemas e perspectivas. Vitória: Edufes, 2015. p. 19-57.

ARENDT, H. Homens em tempos sombrios. São Paulo: Companhia das Letras, 1987.

ARENDT, H. A condição humana. Rio de Janeiro: Forense, 2010.

ARENDT, H. Sobre a Revolução. São Paulo: Companhia das Letras, 2011.

ARISTÓTELES. Ética a Nicômaco. Trad. Antonio de Castro Caeiro. São Paulo: Atlas, 2009.

ASSY, B. Ética, responsabilidade e juizo em Hannah Arendt. São Paulo: Perspectiva, 2015.

BRASIL. Lei n ${ }^{\circ} 13.005$, de 25 de junho de 2014. Aprova o Plano Nacional de Educação - PNE e dá outras providências. Diário Oficial [da] República Federativa do Brasil. Ed. extra. Brasília, 26 jun. 2014. Seção 1, p. 1.

BAUMAN, Z. Em busca da política. Rio de Janeiro: Jorge Zahar Editor, 2000.

BRAYNER, F. Educação e republicanismo: experimentos arendtianos para uma educação melhor. Brasília: Líber Livro Editora, 2008.

FREITAS, M. S. de. A hospitalidade em Homero. Ítaca. Revista de Pós-graduação em Filosofia. Rio de Janeiro: IFCS - UFRJ, n. 27, p. 33 - 42, 2014. Disponível em: <https:// revistas.ufrj.br/index.php/Itaca/article/view/>. Acesso em: 05 de jun. 2016.

GAMA, A. de S. Trabalho e responsabilidades familiares no Brasil: reflexões sobre os direitos do trabalho. Em Pauta, Rio de Janeiro, v. 10, n. 30, p. 149-168, 2. semestre de 2012. Disponível em: <http://www.e-publicacoes.uerj.br/index.php/revistaempauta/ article/view/ 5110/3750>. Acesso em: 07 maio 2016.

GENTILI, P. O direito à educação e as dinâmicas de exclusão na América Latina. Educação \& Sociedade, Campinas, v. 30, n. 109, set./dez. 2009. Disponível em: <http:// www.scielo.br>. Acesso em: 10 maio 2016.

KUHLMANN JUNIOR, M. Histórias da educação infantil brasileira. Revista Brasileira de Educação, Rio de Janeiro: ANPED; Campinas, n. 14, p. 5-18, maio/jun./jul./ago. 2000. Disponível em: <http://www.scielo.br/pdf/rbedu/n14/n14a02>. Acesso em: 14 jun. 2016.

MATOS, O. Discretas esperanças: reflexões filosóficas sobre o mundo contemporâneo. São Paulo: Nova Alexandria, 2006.

MATOS, O. Contemporaneidades. São Paulo: Lazuli Editora; Companhia Editora Nacional, 2009. 
ORTEGA, F. Genealogias da amizade. São Paulo: Iluminuras, 2002.

ORTEGA, F. Para uma política da amizade: Arendt, Derrida, Foucault. Rio de Janeiro: Sinergia: Relume Dumará, 2009.

QVORTRUP, J. A dialética entre a proteção e a participação. Currículo sem Fronteiras, v. 15, n. 1, p. 11-30, jan./abr. 2015.

SENNETT, R. O declínio do homem público: as tiranias da intimidade. São Paulo: Companhia das Letras, 1988.

SIERRA, V. M. A judicialização da infância: o processo de implantação e execução do Estatuto da Criança e do Adolescente nas cidades do Rio de Janeiro, Niterói e Maricá. 191 f. Tese (Doutorado em Ciências Humanas - Sociologia) - Programa de Pós-Graduação em Ciências Humanas, Instituto Universitário de Pesquisa do Rio de Janeiro, Rio de Janeiro, 2004.

SOARES, N. F. Os direitos das crianças nas encruzilhadas da proteção e da participação. Zero-a-Seis, Florianópolis, v. 7, n. 12, p. 8-18, jul./dez. 2005.

SPOSATI, A. Vida urbana e gestão da pobreza. São Paulo: Cortez, 1988.

SPOSATI, A. Assistência social: de ação individual a direito social. Revista Brasileira de Direito Constitucional, São Paulo, n. 10, p. 435-458, jul./dez. 2007.

TELLES, V. da S. Direitos sociais: afinal do que se trata? Belo Horizonte: Ed. UFMG, 1999.

Texto recebido em 20 de junho de 2016. Texto aprovado em 27 de agosto de 2016. 
